Narrative Works

Issues, Investigations, \& Interventions

\title{
Older Women's Situated Identities: Positioning Analysis Applied to Stories about Everyday Experiences Dealing With Physical Functional Changes
}

\section{Makie Kawabata and Miya Narushima}

Volume 8, Number 1-2, 2018

URI: https://id.erudit.org/iderudit/1059849ar

DOI: https://doi.org/10.7202/1059849ar

See table of contents

Publisher(s)

Centre for Interdisciplinary Research on Narrative, St. Thomas University

ISSN

1925-0622 (digital)

Explore this journal

Cite this article

Kawabata, M. \& Narushima, M. (2018). Older Women's Situated Identities: Positioning Analysis Applied to Stories about Everyday Experiences Dealing With Physical Functional Changes. Narrative Works, 8(1-2).

https://doi.org/10.7202/1059849ar

\section{Article abstract}

Identities are not only constructed through coherent and unified stories about significant events but also formed within the interactions during everyday social encounters. Using positioning analysis, we explored how older women's "small stories" from interviews can be used to identify their "situated selves" and how positioning analysis contributes to enhance our understandings about their experiences of physical functional changes. Positioning analysis helped us see how they continuously modify their positions to reconstruct their identities while they talk about everyday life. We should pay more attention to "small stories" about everyday activities as well as their coherent "big stories."
This document is protected by copyright law. Use of the services of Érudit (including reproduction) is subject to its terms and conditions, which can be viewed online.

https://apropos.erudit.org/en/users/policy-on-use/ 


\title{
Older Women's Situated Identities: Positioning Analysis Applied to Stories about Everyday Experiences Dealing With Physical Functional Changes ${ }^{1}$
}

\author{
Makie Kawabata \\ Kansai University of International Studies
}

Miya Narushima

Brock University

\begin{abstract}
Identities are not only constructed through coherent and unified stories about significant events but also formed within the interactions during everyday social encounters. Using positioning analysis, we explored how older women's "small stories" from interviews can be used to identify their "situated selves" and how positioning analysis contributes to enhance our understandings about their experiences of physical functional changes. Positioning analysis helped us see how they continuously modify their positions to reconstruct their identities while they talk about everyday life. We should pay more attention to "small stories" about everyday activities as well as their coherent "big stories."
\end{abstract}

Functional changes in later years can cause significant and lifechanging experiences for older people. We explored how older people reconstruct a sense of self through telling stories about how they experience physical functional changes. We think this helps us understand how people grow old and the impacts of social structure on the process. We applied an analytical approach based on the concept of narrative identity. Narrative identity is "a person's internalized and evolving life

1 We would like to offer our sincere gratitude to the participants in this study, who generously shared their life experiences. We also thank the organizations and their staffs who assisted in our recruitment. This study was funded by a grant from the Japan Society for the Promotion of Science (Grant-in-Aid for Challenging Exploratory Research).

NARRATIVE WORKS: ISSUES, INVESTIGATIONS, \& INTERVENTIONS 8(1/2), 61-82

CMakie Kawabata \& Miya Narushima, 2018 
story" through which "people convey to themselves and to other who they are now, how they came to be, and where they think their lives may be going in the future" (McAdams \& McLean, 2013, p. 233). We also viewed identity as "multiple, fragmentary, unfinished, always changing rather than a fixed, unified, coherent or stable essence which serves as origin or accomplishment of experience" (Smith \& Sparkes, 2008, p. 24).

We began our analysis using dialogic/performance analysis which was introduced by Riessman (2008), but found that not all participants told their stories with certainty. Some participants were more inclined to tell stories about their past than talking about the present and future. We initially thought these were "failed" interviews, because the stories were not consistent with what the conventional approach defines as narrative. In conventional narrative, "coherence [is] assumed as a norm for good and healthy lives" and "good and competent narrative always proceeds in a linear, chronological way" (Hyvarinen, Hyden, Saarenheimo, \& Tamboukou, 2010, p. 1). Our participants did not explain their experiences as unified and coherent stories, but rather gave us brief responses to our questions throughout the interviews. However, upon revisiting their stories, we realized that although these parts did not contain rich descriptions and were not long enough to identify sequences of events and, therefore, did not help us see a coherent and unified whole, they provided an opportunity for us to understand how those women constructed a "situated self" (McLean \& Thorne, 2006; Pasupathi, 2006), which is "situated in the everyday social world as people communicate with each other." The narrative-in-interaction process became the methodological solution.

The narrative-in-interaction process analyzes small stories, which is "an umbrella-term that captures a gamut of under-represented narrative activities, such as telling of ongoing events, future or hypothetical events, shared events" (Georgakopoulou, 2006, p. 1). It was developed as an alternative to the classical narrative approach and has been advocated by Bamberg and Georgakopoulou (Bamberg, 2011; Georgakopoulou, 2006). While the conventional narrative approach examines stories from the past as retrospective and reflective of events that contain significant and lifechanging experiences, the narrative-in-interaction approach analyzes how stories unfold in everyday activities. Small stories allow researchers to identify and display the discursive processes of situated and contextualized identities which develop in everyday social encounters (Bamberg \& Georgakopoulou, 2008). It assumes that people construct their identities through navigation processes that are three dimensional: 
(a) a dialectic process of continuity and change; (b) a synchronic process of self-differentiation and integration; and (c) "agency-dilemma," where speakers position themselves, or social and cultural constraints position "the subject" (Bamberg, 2011, p. 7). The narrative-in-interaction approach posits that people constantly reconstruct "who they are" through these three-dimensional navigation processes as they conduct everyday activities. By iterating these processes, people potentially establish a sense of constancy and sameness (Bamberg, 2011, p. 14), which leads to a unified and coherent identity.

We posed two research questions in this study. First, does analysis of small stories from the interviews help us to understand the process of older people's identity construction? Second, how do small stories analyzed using positioning analysis contribute to our understandings about older people's lives as they undergo physical functional changes? To answer these questions, we will illustrate the narrative-in-interaction (positioning analysis) process using two older Japanese women's narratives, which were anything but coherent and unified and might have been dismissed as failed interviews using conventional narrative methods. We will also discuss possibilities and a challenge to using positioning analysis when examining older peoples' small stories.

\section{Methods}

The narrative analysis used in this paper is based on interviews with 21 older Japanese women living in Japan, all of whom were experiencing some physical functional changes. They ranged in age from 65-94, and all continued to live in their homes. They were recruited through local daycare centers, a home-care support center, and a medical clinic, all in urban areas. Criteria for participant recruitment were that they be at least 65 years old, beneficiaries of Long-Term Care Insurance services, without cognitive impairment, possessed of sufficient strength for a two-hour interview, and capable of providing informed consent. The study was approved by the Research Ethics Boards of the relevant research institution. There have been discussions about the definition of old age (Ouchi et al., 2017). However, in Japan, 65 is the accepted cultural norm for being "old" and the Long-Term Care Insurance system defines people 65 and older as legitimate beneficiaries of the service. Accordingly, we included only people over 65 as a criterion for participation. The interviews lasted between 60 and 120 minutes and took place in the participants' homes. The researchers used a semi-structured 
interview guide to cover common questions, such as "How do you see the changes to your health and physical conditions?" and "How do you manage everyday life?" We also encouraged participants to discuss their lives-past, present, and future. All interviews were audio-recorded and transcribed verbatim. The stories were edited to protect the personally identifiable information of the participants.

\section{Positioning Analysis}

Positioning analysis was developed by Bamberg and Georgakopoulou (Bamberg, 1997; Bamberg, 2004; Bamberg \& Georgakopoulou, 2008) to analyze small stories in which identities are emerging and managed through narrative-in-interaction. This is opposed to big stories, in which people are considered independent and construct their identities "by way of orienting their memories backward, engaging in cognitive activities of reflecting" (Bamberg, 2006, p. 172). Positioning refers to "the assignment of fluid 'parts' or 'roles' to speakers in the discursive construction of personal stories that make a person's action intelligible and relatively determinate as social act" (van Langenhove \& Harre, 1998, p. 17). Positioning analysis allows researchers to explore how narrators construct who they are by examining the way they construct their world, their place in it in relation to others, and the way they interact with listeners in forming their stories. Through those examinations, researchers can explore how narrators' work leads to a shared, and possibly coherent, identity. The approach consists of three levels. At Level 1, the analysis tries to determine how people frame an issue and position themselves within the issue when they construct a sense of self during a conversation. At Level 2, the analysis explores how narrators and listeners co-construct who they are during the interaction. At Level 3, the approach aims to identify the linkage between cultural and normative discourses and narrators' positioning practices.

We will illustrate positioning analysis using the narratives of two older Japanese women, Egawa and Kato. Their stories demonstrated cohesiveness, with a logical ordering of events, desirable end points, and a sense of clear direction, using conventional methods to view wellformed narratives. But when it came to conversations about their ongoing experiences with physical functional change and their expectations for the future, they showed hesitation, rejection, and confusion and, therefore, did not elaborate their experiences with confidence. Their answers were relatively short and not concentrated but dispersed throughout the 
interviews and, therefore, their stories were disjointed rather than linear, chronological, and sequential. The stories had plots but there were no concrete resolutions.

Using positioning analysis, we first extracted parts of conversations, those containing topics associated with current experiences and projections for the future that relate to physical functional changes. For this paper, we selected excerpts associated with ongoing experiences and future projections. However, we needed to omit some parts because of space limitations. We analyzed each segment (excerpt) of the conversations from Level 1 to Level 3. For Level 1, we identified how the narrators framed their story, what the story was about, and how the narrators characterized themselves and others, as well as how they positioned themselves and how they were positioned by society and prevailing social norms. At Level 2, we reread the excerpts in order to understand how the participant and the interviewer co-constructed meanings for the ongoing events and the future, in order to understand how the interaction worked for the participant to reconstruct herself. Finally, at Level 3, we identified how broader social contexts affected the way the narrators positioned themselves and others and how they were positioned by social circumstances. We also analyzed how they interacted with the interviewer in order to understand the impact of the normative and political discourse on their self-images. In the following section, we give a summary of each woman's background, followed by excerpts extracted from the interview transcripts and the findings from positioning analysis.

\section{Egawa}

Egawa, an 89-year-old widow, lived with her daughter's family in a two-household home in a suburb. She had fallen several times, and one fall damaged her spine. Although she was now pain free and functioning quite well, she needed her daughter's help when she wanted to walk outside. While talking proudly and eloquently for most of the interview about her memories of her husband, she spoke little about her daily life after her falls: 


\section{Excerpt $1^{2}$}

1 I: Are you still going outside by yourself?

2 E: (My daughter) doesn't allow me to do so even if I said I want [laughing]. (It is

3 because) She (her daughter) will have troubles later. (She) has started a business

4 (teaching a tea ceremony) ....and was asked to give some lessons at a community center

5 nearby.... and do it about three times at home too.

6 I: So, are you afraid of going out now? Or, you don't care?

7 E: I don't worry much about it. But, I feel sorry (for her daughter) if I fall (again), and

8 then I became cautious...

9 I: Everybody worries about you, do they?

10 E: Yes. They (her daughter and her son-in-law) said, "(We) don't take care of you (if you

11 do it again)." So, and then, it's hard (for you) to imagine, though, I've been alone (all day

12 long at home), and then, I sometime talk back to even TV...[laughing].

\section{Excerpt 2}

$1 \mathrm{I}$ : What concerns you most in your present physical condition?

$2 \mathrm{E}: \mathrm{Hmm}$... I sometime think that I want to die soon...

3 I: Do you? [in a confused tone].

4 E: No ...I like travel and Kabuki (Japanese traditional theatre) although you may not

5 think that I am that kind of person (to watch Kabuki)

6 I: (You said, "I want to die soon") because you can't do it anymore?

2 I: Interviewer (the first author)

E: Egawa

K: Kato

... a short pause

[...] omission of sentences

[ina] an inaudible sentence

( ) supplementary information to clarify meanings

[ ] tones of voices 
7 E: Well, you said "I can't" ...because it's not easy for my daughter to take me there. If

8 my friend knows that I am going, she (the friend) would go along. But then I would need

9 my daughter to take both of us. It would be difficult. So, I can't.

\section{Excerpt 3}

1 I: What are you going to do when your physical condition worsens? For example, what if

2 you become unable to move?

3 E: I told my daughter to put me in a nursing home [with a sardonic smile].

4 I: Do you expect your daughter to take care of you in this house?

5 E: Well ...that's why we (she and her late husband) bought her the house...My husband

6 left money when he passed away...I divided some of that with her and her husband.

7 I: You've got it made, haven't you?

$8 \mathrm{E}:$... it may be ...they say that I should not talk about the money. Yes, ...my son-in-law

9 isn't a bad person. He sweeps the backyard once a week.

\section{Positioning Level 1.}

In Excerpt 1, responding to the interviewer's question which asked if she was capable of going outside by herself or needed someone's help, Egawa raised the topic of a family caregiver, her daughter. In the story, Egawa characterized herself as a caring mother who was sensitive to her daughter's career, even though her work did not allow Egawa to maintain her social life. She also described her daughter as a successful business woman.

In Excerpt 2, line 2, when stating that she wanted to die soon, Egawa presented her belief that her life was not worth living. After the interviewer's response in a confused tone, however, Egawa withdrew that position and tried to impress the interviewer, indicating that she used to enjoy a social life. Demonstrating her appreciation for Kabuki, Egawa recalled that she was a sophisticated and intelligent woman from the middle class. In this exchange, Egawa shifted her position from being a 
"hopeless" older mother to a caring and sophisticated person in lines 7-9. This statement led her to face a dilemma between being a mother who cares about her children and being a social woman who has a right to maintain the life she had enjoyed.

In Excerpt 3, she described herself as a powerful woman who controlled her family using her economic power. In this conversation, Egawa firmly believed that she has a right to be cared for by her children. In line 3, she said "I told my daughter to put me in a nursing home [with a sardonic smile]." The sardonic smile suggested she believed her daughter did not have the courage to do so, given that Egawa owns their house. However, at the end of the interaction, she relaxed her powerful tone and tried to correct the negative image she had painted of her family, saying that her son-in-law was a good person. In this excerpt, she shifted herself from being a powerful woman to an understanding mother who is sensible about her family's caregiving efforts.

\section{Positioning Level 2.}

In Excerpt 1, the interviewer's use of the term "by yourself" suggested that Egawa might need someone's help to go out. In return, Egawa positioned herself as a person who was cared for by her family and described her daughter as a responsible caregiver. In line 3, when the interview was flowing to the topic of her daughter's business and in line 6, the interviewer controlled the conversation and asked Egawa about her feeling of going outside by herself: if she had difficulties since she had fallen twice. In line 7, Egawa resisted the image that the interviewer tried to attach to her as being frail. Instead, she expressed concern for her daughter and son-in-law. In this exchange, she tried to convey that her limited social life was not her fault but her daughter's. In line 9, the interviewer redirected the discussion, suggesting Egawa was fortunate to have a good daughter. This reflects the interviewer's internalized social norm of family caregivers. The interviewer unconsciously imposed the normative discourse that children should take care of their parents, and parents should relinquish power to their children in return. As a result, in line 10, Egawa admitted that she was indeed fortunate to live with her daughter and son-in-law. However, at the same time, Egawa indirectly disagreed with the interviewer and tried to convey her effort to manage a life with limited social engagement. She did not believe that she deserved this, but seemed uncertain how to discuss it with the interviewer. 
In Excerpt 2, line 3, the interviewer expressed her confusion in response to Egawa's statement, "...I want to die soon." Given her social background, it was unusual for a woman like her to talk about personal feelings in the first encounter. The interviewer sensed that Egawa could elaborate her story into a complex issue of family dynamics but did not expect her to speak of such personal problems. The interviewer showed her feeling of confusion and sent her a signal, saying "Do you?" with a confused and ambiguous tone, indicating that the interviewer was not ready to accept Egawa's explanation. As a result, Egawa retracted her statement, saying "No," and tried to ease the interviewer's confusion by explaining her reasons. In line 6, the interviewer reassured Egawa. In lines 4-5, Egawa emphasized that watching Kabuki had been an important part of her life. This indicated that it contributed to her identity construction regarding the past, which was evident as she talked about it in another part of the interview. In line 7, however, Egawa again stated she could not control her social life and her daughter was the one in charge. This time, however, Egawa's tone became soft and caring. In this excerpt, she shifted her position from an old mother whose life was determined by forces beyond her control to a woman from the middle class who tried to manage her changing lifestyle with a limited social life.

In Excerpt 3, the interviewer asked her how she was managing her physical functional changes. It was a challenge for Egawa because she did not have the independence to make all her own decisions. In line 3, Egawa talked back to the interviewer, venturing to say, "I told my daughter to put me in a nursing home." But, her sardonic smile indicated that it was not her real wish and implied that nobody in her family could put her in a nursing home because she owned the family home. The interviewer tried to reassure her in line 4. In this interaction, Egawa revealed her self-image as a powerful woman. Obtaining the interviewer's affirmation for her explanation in line 7, Egawa modified her somewhat arrogant behavior and reverted to behaving like a "normal" sophisticated woman. The interviewer's challenge pushed Egawa to characterize herself as a powerful woman who could exercise control, which is different from her characterization in Excerpts 1 and 2.

\section{Positioning Level 3.}

There are social and cultural imperatives associated with Egawa's positioning in these excerpts. First, social expectations and norms for women have been changing since the 1960s and 70s (Kono, 2000), when 
Egawa learned to be a "good" daughter and female partner. Currently, women are more likely to participate in the workforce in Japan (Tsutsui, 2014) and, therefore, living with family is no longer assured for the elderly. However, Egawa still accepted the traditional cultural norm. She took it as a given that her daughter would take care of her, since that was the custom when she was young. This is evident in the conversation where she feels sorry for her daughter but never expresses gratitude for her caregiving.

Second, the current Long-Term Care Insurance system does not provide users with services for socialization or cultural activities other than adult daycare services (Health and Welfare Bureau for the Elderly, Ministry of Health, Labour, and Welfare, 2018). In addition, the existing service is limited to recipients who have no family to live with (Sahashi, 2012). People like Egawa must rely on their families. This is based on the premise that people should be responsible for their health and for maintaining a good quality of life in later years (Hattori, 2006). In this context, it is not unreasonable for Egawa to face a dilemma between being a good mother who allows her daughter to prioritize her career, and her wish to be an independent woman and enjoy a social life. In the end, she seemed to accept the normative discourse and was searching for a new identity more in line with her physical capabilities.

\section{Kato}

Kato was 94 years old and living with her daughter in subsidized housing. Kato narrated her difficult life in her youth into a coherent and unified story with positive resolutions. However, it took considerable effort for the interviewer to turn Kato's attention to speaking about how she felt given her current physical condition. In the latter half of the interview, she became responsive to the questions, but she changed the subject frequently and the interviewer was not sure if she was comfortable with the questions. Although the two following excerpts were relatively coherent, she constructed who she was differently, revealing her dilemma about her future:

\section{Excerpt 1}

$1 \mathrm{I}$ : ...I think that you're having difficulty conducting daily activities. What are the most 2 difficult things for you about your present condition? 
$3 \mathrm{~K}$ : I've given up.

4 I: You've given up? Hmm...

$5 \mathrm{~K}$ : There is no way to get my health back.

6 I: Yes, you are right.

$7 \mathrm{~K}$ : Now you are talking! A man who delivers my medication (a visiting pharmacist) asked

8 me, "Are you getting better?" So, I replied, "What're you talking about? I'm getting old.

9 How could you ask that? Get out!" He laughed. [Laughing loudly]

(The interviewer tried to ask Kato how the pharmacist replied to her, but, she did not understand the question and the interviewer repeated it. After a few exchanges, Kato finally answered.)

$10 \mathrm{~K}$ : (He said) "That's right, that's right." I don't have to ask (him) because I knew it. I

11 can't stand up by myself anymore. I can walk with a cane but I can't do it by myself. I

12 try to go straight but my legs move sideways.

13 I: Don't you feel difficult about it?

$14 \mathrm{~K}$ : That's why I have nothing to do all day long other than wake up in morning [ina] and

15 go to a bed in evening. I repeat that every day. There is no way to change this life. My

16 life is over [in a detached tone]. That's what I think. I can't think of any other options. I

17 wish I could die soon, but it's not possible, right?

18 I: Some people try to fix their problems with physiotherapy. What do you think about

19 that?

$20 \mathrm{~K}$ : Is that so?

$21 \mathrm{I}$ : Aren't you interested in that?

$22 \mathrm{~K}$ : I can't understand why people want to live any longer.

23 I: Well, you may be right.

$24 \mathrm{~K}$ : I want to go to the heaven soon. I have had enough already.

25 I: Are you satisfied with your life?

$26 \mathrm{~K}$ : (She was trying to say "yes") It doesn't mean I played around. I was born in a small 
27 village and I was told that I should marry a man in a village, but I refused. Since it has

28 come to this.

\section{Excerpt 2}

1 I: If you didn't have your daughter to live with, do you think that you would be in a

2 nursing home now?

$3 \mathrm{~K}$ : So, I said (to my daughter), she should put me there (a nursing home.)

4 I: I see. You said so.

(Kato changed the subject, saying that she has been demented in an amusing way and started talking about her relatives who had dementia. The interviewer tried to get back to the subject of moving to a nursing home.)

5 I: Do you want to stay here? Do you prefer to stay at home rather than moving to a

6 nursing home?

$7 \mathrm{~K}$ : [iau] I'm fine to go (to a nursing home). I'm just waiting to die.

8 I: I see.

$9 \mathrm{~K}$ : It is not a good idea to cause trouble for my daughter. (My daughter worried about it

10 and) said she can't take care of me (if I go to a nursing home), but I said it's OK. I am

11 going to die anyway. I have been through (many things) ... and I won't pay for it. If I go

13 there, I can't [ina], can I.

(The interviewer explained to Kato about typical family who choose a nursing home and some ways of life there.)

$14 \mathrm{~K}$ : Whatever it is, I said that I am OK.

15 I: You may be able to stay here if someone (home assistances) can visit here every day.

$16 \mathrm{~K}$ : What do I have to do with them?

17 I: Do you feel annoying (to use the services)?

$18 \mathrm{~K}$ : I feel easy staying here, I do nothing, though.

19 I: I see. You feel easy.

$20 \mathrm{~K}$ : I think these days, I should leave it to chance. 
(After this conversation, the interviewer asked when she started feeling that way. Then, Kato went back to stories about her pastlike how she took care of her husband for awhile. And she suddenly came back to the subject of moving to a nursing home.)

$21 \mathrm{~K}$ : [Her tone of voice has been low and serious]. My doctor told me that I would not be

22 able to choose a good one (nursing home) because I'm on public assistance (welfare).

23 [iau].

24 The doctor said that I shouldn't expect anything better than that [in a small voice].

25 I: Do you mean that's because you are on welfare? The welfare office chooses the nursing

26 home (instead of you), does it?

$27 \mathrm{~K}$ : I feel like "I don't care." [iau]. I admit I have sometimes worried about it. [iau]. [iau]. I

28 wish I could die of some disease (so that I could die in a hospital rather than moving to a

29 nursing home). [iau]. I have tried not to be bedridden.

30 I: I see. I understand.

\section{Positioning Level 1.}

In Excerpt 1, Kato described her life with physical functional changes as a loss of independence, as she emphasized her inability to do things by herself. In line 3, Kato clearly stated that she "gave up" and offered an explanation in line 5. In lines 7-9, she cited a conversation with a pharmacist which she reported in a humorous and self-deprecating way. This positive emotion can be considered as her capacity to "recover and bounce back from daily stress" (Ong, Bergeman, Bisconti, \& Wallace, 2006, p. 743) and her way of resisting the active/successful aging ideology, where older people's experiences are measured in terms of individual efforts to continue productive activities (Katz \& Calasanti, 2015). In Lines 10-12, Kato emphasized the impact of changes in her physical functions using the term "I can't... by myself" repeatedly. In line 13, the interviewer further probed her perceptions of her physical functionality and Kato stated that her life had no meaning if she lost her ability to do things by herself. This is considered narrative foreclosure, which is defined as the status of narrative identity construction featuring the conviction that "there are no more meaningful commitments and 
experiences in the past and the future" (Bohlmeijer, Westerhof, Randall, Tromp, \& Kenyon, 2011). In line 18, the interviewer tried to give Kato a different perspective, asking about physiotherapy if she was interested in improving her physical functioning. By doing this, the interviewer unconsciously imposed Japan's prevalent ideology of "active aging" on Kato, who rejected the idea. In line 26, Kato shifted the conversation back to her past life as a strong and independent woman, where she felt more comfortable than in talking about the present. Kato drew on her past stories to avoid positioning herself as an older woman whose life has no meaning. She tried to reconstruct herself, replacing the stories of narrative foreclosure with her past, where she had a positive self-image. This could be her way of resisting the idea of aging.

In Excerpt 2, Kato described her life differently than in Excerpt 1, and her positioning was also different. In this part of the conversation, she revealed that her life was in the middle of uncertainty and it was therefore difficult to position herself in the story. In lines 1-2 and 5-6, the interviewer asked her if she wanted to stay at home or move to a nursing home. For Kato, moving to a nursing home was not what she was hoping for. It was evident in her account_- "She should put me there"-implying that it was not something she could decide, but that the decision would depend on her daughter. It seemed that she did not know how to position herself in this conversation. This is in stark contrast to her position in Excerpt 1, in which she was the one who decided how she would live. In lines 9-11, she talked about why she was not moving to a nursing home and implied that money would be the issue. The interviewer further asked Kato about her use of the long-term care service, including a homehelper. She did not know how it worked. She seemed not to think much about her future, preferring to leave it to chance. She also changed the topic and talked about her late husband for awhile. Then she suddenly came back to the subject with a serious tone. She used her doctors' opinion, revealing that her lack of financial resources was an obstacle to applying to a nursing home. Kato positioned her family doctor as an authority. In this exchange, she faced the challenge squarely. Her financial constraints under welfare assistance limited her choices. In a sense, her life was not over, as she asserted in Excerpt 1, but was continuing as she faced the reality of becoming a person in need of care. 


\section{Positioning Level 2.}

In Excerpt 1, line 1, the interviewer tried to elicit stories about Kato's changing physical function. In line 2, Kato sounded desperate to answer the question saying, "I've given up" in line 2 and "There is no way to get my health back" in line 5. The interviewer showed her affirmation by responding with the phrase "You are right," and it encouraged Kato to talk about the visiting pharmacist to emphasize the legitimacy of her situation. After the interviewer showed her interest in this conversation, in lines 10-12, Kato elaborated on her inability to do things by herself, repeatedly using the term "I can't." In these exchanges, Kato described her current physical functional status as troubled. In line 13, the interviewer tried to determine how Kato felt about her status. Kato justified her current lifestyle of lying in bed all day. In this exchange, she revealed her belief that people should not lie in bed all day but should be active and productive, thus reflecting the dominant belief about active aging. The last sentence in lines 16-17, “...but it's not possible, right?" indicated that she tried to get reassurance that she was right. Because her answer was unexpected, the interviewer probed by asking about the possibility of physiotherapy. In doing so, the interviewer unconsciously further imposed the normative standard of active aging. Kato again refused the idea. In line 25, the interviewer tried to determine if her saying "I had enough" was related to her past life or the future. Then, Kato in lines 26-28, went back to her old story and re-established herself as a strong woman. Through these conversations, responding to the interviewer, Kato tried to deal with her current physical functional changes but had not found a way to accept losing her autonomy.

In Excerpt 1, the interviewer first asked Kato about moving into a nursing home as one of her possible options. Kato replied that it was her daughter's decision and then changed the subject. In line 5, the interviewer tried to elicit more details with a similar question. She replied with the statement that it was not her concern, because she was dying soon anyway. But this time, she went into greater detail, indicating that being dependent on her daughter was not ideal, but that she could not pay for a nursing home. After the interviewer explained the limitations of the nursing home system (which was omitted from the excerpt-the interviewer positioned herself as an expert on the system), Kato finally spoke about her future constraints. Hearing the explanation, she

nonetheless insisted that she did not care about moving into a nursing home. In this conversation, she began to be realistic but was not sure 
about how to express herself. This is evident in line 20, in which she indicated that she had been thinking about her future but she left it to chance. After this, she changed the subject and the interviewer thought this was the end of Kato's stories. However, in line 21, she suddenly came back to the narrative after talking about different things, and this time she related the conversation with her family doctor who told her life would not be better in a nursing home. Kato then started facing reality squarely, which brought her into a world of uncertainty. In the end, Kato admitted that she knew that she would not die soon and must manage her physical functional changes with the limited resources available. In this exchange, Kato was not able to maintain her previous strong identity in responding to the interviewer. Kato's resistance was suppressed by the interviewer, who unconsciously expected her to reveal her true feelings about the difficulties of living under the social welfare system.

\section{Positioning Level 3.}

In this conversation, Kato revealed that she did not know how she dealt with losing her autonomy. She was unable to find an alternative so she initially left it to chance. However, as the conversation progressed, she began to face the reality that she would need to be active to maintain her autonomy if she wished to remain at home. One of the social contexts affecting Kato's story telling is Japan's active aging policy in which older people are responsible for their well-being (Cabinet Office, Government of Japan, 2018). In this interview, Kato was defensive about her functional status and its associated lifestyle. She knew that she had to engage in some activities. This discussion, however, led Kato into narrative foreclosure, in which people cannot find meaning in their lives. Positions (roles) available for people to take are "always historically and culturally bound and they reflect the structure of society" (Cohler \& Hammack, 2006, p. 157). Given her limited social life, Kato lacked the flexibility to reconstruct a meaningful life.

Kato's narrative was also affected by the discussion about longterm care services. Although the Japanese Long-Term Care Insurance system was established in 2000 to reduce burdens on family caregivers, the system remains heavily dependent on families remaining involved (Ueno, 2011). While some families can avoid the burden by paying for services from commercial care providers, others with limited resources, like Kato, must depend on informal assistance, predominantly from their family members, to maintain some autonomy. Kato characterized herself 
as an independent and determined woman who had been through a difficult life with limited financial resources. However, as the interviewer tried to elicit her expectations about the future, Kato might have changed her position but did not know what options were available, so could not imagine a different future. This limitation made it difficult for Kato to relate her expectations for the future as a cohesive story.

\section{Conclusions}

Our findings demonstrate that analysis of small stories from interview settings allows us to see the process of how older people construct their identities by negotiating multiple options during brief exchanges with the interviewer. We examined two older women's everyday experiences associated with physical functional challenges, applying positioning analysis to their stories, which could not be analyzed using conventional narrative methods. Our findings demonstrate that the stories provide us with rich information about the process of dealing with constant change and that the fragments do lead to a coherent and unified whole. The two women established several positions during their interviews that shaped and reshaped who they are in various ways. The analysis from Level 1 demonstrated that Egawa described her experiences as an issue of family caregivers whereas Kato viewed her current physical functional status as a crisis, having lost the ability to live independently. In the Level 2 analysis, we found that both women often perceived the interviewer's questions and responses as challenging and they did not always accept the norms or assumptions imposed during the interviews. While doing so, they constantly changed their positions and both were continuously modifying their stories throughout the interviews. Egawa went back and force between being a caring mother and a powerful female head of the household, and finally portrayed herself as a sensible and respectable mother. Kato, meanwhile, portrayed herself as a defiant and strong woman who determined how she would live, resisting the cultural norm of active aging which was embedded in the questions from the interviewer. However, when further challenged about her expectations for the future, she began to face reality and showed her acceptance of the idea of remaining active to maintain the autonomy necessary to remain in her home. As Bamberg (2011) suggested, the two older women's storytelling revealed "the inconsistencies, ambiguities, contradictions, moments of trouble and the tellers' constant navigation and finessing between different versions of selfhood in local interactional contexts" ( $p$. 
14). In the Level 3 analysis, we uncovered the broader social contexts of both women's positions. It was a mix of the traditional female role of caregiving, the active aging policies, and the current political discourse that emphasizes individual responsibility for maintaining physical health. These analyses provide us with insights into how we conduct narrative research for older adults facing physical functional changes in order to enhance our understanding of their experiences.

This paper enhances our understanding of older people's "life as lived" (Bamberg, 2011, p. 12) experiences dealing with physical functional changes. Positioning analysis allows us to see the complex mental processes older people use to construct "situated selves." If we investigated only big stories, we would miss some of the richness of the narrative and have a less complete understanding of the people's selfimages. For instance, Egawa created both a strong woman and a caring mother persona for herself and she went back and forth between them. Through these processes, she came to terms with her limitations and more accepting of her position as a caring mother dependent on her daughter. She seemingly agreed that her self-image was altered. This suggests we can identify the meanings of identity construction in a more meaningful way and appreciate people's efforts to search for their unified and coherent identities. If we focus on only the big stories, we might overlook these pathways. Physical functional changes occur as people age, and constantly affect their experiences and the process of identity reformation. Positioning analysis is a useful tool for researchers to try to capture the dynamic and complex processes of how people experience changing health status as they age.

Additionally, positioning analysis helped us see more clearly how social structure affects people's experiences and therefore, their identity formation. The stories that are available for interpreting our world are influenced by social institutions (Stone-Mediatore, 2003). Positioning analysis explores the influence of social institutions on the pathways of identity construction and modification. There is a paucity of literature discussing social and structural influences on older people's health (Northwood, Ploeg, Markle-Reid, \& Sherifali, 2018) as well as the linkages between broader social contexts and older people's identity formation. Positioning analysis enabled us to search for the contexts behind their experiences. Kato, for example, asserted that she could not do things by herself-not even walk without help - and because of that, her life lacked meaning. We determined this attitude sprang from accepting the dominant public policy of active aging: that people are 
responsible for maintaining good health. We saw how this dominant norm limits older people's experiences of physical functional change. Because the interviewer lives in the same culture and is influenced by the same social norms and public policies, without positioning analysis we might have overlooked the story fragments and simply assumed Kato was a stubborn old woman.

Last, we found a potential challenge for researchers who conduct positioning analysis with small stories in formal interview settings. Researchers, through their questioning, might unconsciously influence participants to adopt certain positions that more reflect the interviewer's values than the participant's. Kato's perspective was that life has no meaning when one loses one's mobility and independence. This came from Kato's internalized belief; however, when the interviewer unconsciously imposed the same idea, it reinforced Kato's attitude. As a result, her story fell into narrative foreclosure (Bohlmeijer et al., 2011). Moreover, Excerpt 2 showed that Kato did not want to talk about the issue. But she finally admitted that she also was worried about it. She fell into a vulnerable position in which she did not seem comfortable. "People are telling stories with goals in mind, and responding to 'their listeners' needs, goals, and demands, as well as the overall context in which their storytelling is unfolding" (Pasupathi, 2006, p. 145). This means researchers should be sensitive to their own beliefs, values, and ideologies and how these affect the interaction with the interviewee during interviews. Compared to big stories, people who unpack their experiences as small stories are more susceptible to being influenced by the interviewer's responses. In addition, content of small stories is different from big stories (McLean \& Thorne, 2006, p. 123). During such interviews, people address topics they may not be ready to discuss and thus find it difficult to relate them as big stories. Thus small stories result as participants struggle to express themselves coherently. Researchers need to understand their own beliefs, values, and ideologies in order to understand their influence on study participants (Shojima, 2008), and "must offer reflexive accounts of how we and the participants in our research affect one another and the stories being told" (Blix, 2016, p. 45).

We, as qualitative researchers from the public health field, are trying to understand how older people exercise their agency as they live with physical functional changes and how the broader social contexts, including public policies, affect their experiences. This paper helped us to see positioning analysis with small stories as a useful analytic strategy 
and a way to develop empirical evidence to improve public policies on aging.

\section{References}

Bamberg, M. (1997). Positioning between structure and performance. Journal of Narrative and Life History, 7(1-4), 335-342.

Bamberg, M. (2004). Form and functions of "slut bashing" in male identity constructions in 15-year-olds. Human Development, 47(6), 331-353.

Bamberg, M. (2006). Stories: Big or small: Why do we care? In M. Bamberg (Ed.), Narrative: State of the art (pp. 165-174). Amsterdam, The Netherlands: John Benjamins.

Bamberg, M. (2011). Who am I? Narration and its contribution to self and identity. Theory \& Psychology, 21(1), 3-24.

Bamberg, M., \& Georgakopoulou, A. (2008). Small stories as a new perspective in narrative and identity analysis. Text \& Talk, 28(3), 377-396.

Blix, B. H. (2016). The importance of untold and unheard stories in narrative gerontology: Reflection on a field still in the making from a narrative gerontologist in the making. Narrative Works, 6(2), 28-49.

Bohlmeijer, E. T., Westerhof, G. J., Randall, W., Tromp, T., \& Kenyon, G. (2011). Narrative foreclosure in later life: Preliminary considerations for a new sensitizing concept. Journal of Aging Studies, 25, 364-370.

Cabinet Office, Government of Japan. (2018). White paper: Annual report on the aging society. Retrieved from https://www8.cao.go.jp/kourei/whitepaper/indexw.html [in Japanese]

Cohler, B. J., \& Hammack, P. L. (2006). Making a gay identity: Life story and the construction of a coherent self. In D. P. McAdams, R. Josselson, \& A. Lieblich (Eds.), Identity and story: Creating self in narrative (pp. 151-172). Washington, DC: American Psychological Association.

Georgakopoulou, A. (2006). Thinking big with small stories in narrative and identity analysis. Narrative Inquiry, 16(1), 122-130.

Hattori, K. (2006). A duty to promote health and prevent disease [in Japanese]. Bioethics, 16(1), 178-184.

Health and Welfare Bureau for the Elderly, Ministry of Health, Labour, and Welfare. (2018). Partial Amendment to Criteria for Home Attendant Services. Retrieved from https://www.mhlw.go.jp/stf/seisakunitsuite/bunya/hukushi_kaigo/shougaishahu kushi/kaisei_seisin/ [in Japanese]

Hyvarinen, M., Hyden, L.-C., Saarenheimo, M., \& Tamboukou, M. (2010). Beyond narrative coherence: An introduction. In M. Hyvarinen, L.-C. Hyden, M. Saarenheimo, \& M. Tamboukou (Eds.), Beyond narrative coherence (pp. 115). Amsterdam, The Netherlands: John Benjamins.

Katz, S., \& Calasanti, T. (2015). Critical perspectives on successful aging: Does it "appeal more than it illuminates"? The Gerontologist, 55(1), 26-33.

Kono, M. (2000). The Impact of modernisation and social policy on family care for older people in Japan. Journal of Social Policy, 29(2), 181-203. 
McAdams, D. P., \& McLean, K. C. (2013). Narrative Identity. Current Directions in Psychological Science, 22(3), 233-238.

McLean, K. C., \& Thorne, A. (2006). Identity light: Entertainment stories as a vehicle for self-development. In D. P. McAdams, R. Josselson, \& A. Lieblich (Eds.), Identity and story: Creating self in narrative (pp. 111-127). Washington, DC: American Psychological Association.

Northwood, M., Ploeg, J., Markle-Reid, M., \& Sherifali, D. (2018). Integrative review of the social determinants of health in older adults with multimorbidity. Journal of Advanced Nursing, 74(1), 45-60.

Ong, A. D., Bergeman, C. S., Bisconti, T. L., \& Wallace, K. A. (2006). Psychological resilience, positive emotions, and successful adaptation to stress in later life. Journal of Personality and Social Psychology, 91(4), 730-749.

Ouchi, Y., Rakugi, H., Arai, H., Akishita, M., Ito, H., Toba, K., \& Kai, I. (2017). Redefining the elderly as aged 75 years and older: Proposal from the Joint Committee of Japan Gerontological Society and the Japan Geriatrics Society. Geriatrics \& Gerontology International, 17(7), 1045-1047.

Pasupathi, M. (2006). Silk from sow's ears: Collaborative construction of everyday selves in everyday stories. In D. P. McAdams, R. Josselson, \& A. Lieblich (Eds.), Identity and story: Creating self in narrative (pp. 129-150). Washington, DC: American Psychological Association.

Riessman, C. K. (2008). Narrative methods for the human sciences. Los Angeles: Sage.

Sahashi, K. (2012). The limitation of choice and client-oriented principle in the elderly care insurance system in Japan: From the perspective of quasi-market theory [in Japanese]. Hokusei Ronsyu, 49, 99-114.

Shojima S. (2008). Multilayered contexts in which narrative is generated and interpreted: Toward the next narrative based inquiry. Kyoto University Research Studies in Education, 54, 138-151.

Smith, B., \& Sparkes, A. C. (2008). Contrasting perspectives on narrating selves and identities: An invitation to dialogue. Qualitative Research, 8(1), 5-35.

Stone-Mediatore, S. (2003). Reading across borders: Storytelling and knowledges of resistance. New York: Palgrave.

Tsutsui, J. (2014). Female labor participation and sexual division of labor: A consideration on the persistent male-breadwinner model [in Japanese]. Nihon Rodo Kenkyu Zasshi [The Monthly Journal of the Japan Institute of Labour], 56(7), 70-83.

Ueno, C. (2011). Sociology of care: Toward a welfare state with self governance [in Japanese]. Tokyo, Japan: Ota Shuppan.

van Langenhove, L., \& Harre, R. (1998). Introducing positioning theory. In L. van Langenhove \& R. Harre (Eds.), Positioning theory: Moral contexts of intentional action (pp. 15-31). Oxford, England: Blackwell.

Makie Kawabata, $\mathrm{PhD}$, is a professor in the Faculty of Health Science, Kansai University of International Studies, Japan. She completed her $\mathrm{PhD}$ in the Faculty of Nursing at the University of Toronto. Her research interests lie in the area of public health, including health inequalities, social determinants of health, social justice, and community empowerment. She uses critical social theory to analyze qualitative data obtained from marginalized populations such as the homeless and the elderly to uncover structural influences on their life 
experiences and health. Her works also include exploratory research on qualitative methodologies in different cultural settings.

Miya Narushima, $\mathrm{PhD}$, is an associate professor in the Department of Health Sciences, Brock University, Ontario, Canada. She grew up in Japan, moving to Canada in her 20s. She obtained her PhD in Adult Education and Community Development from OISE/University of Toronto. Her research areas include aging and wellbeing, later life learning and development, community-based health promotion, community capacity building, voluntarism, social determinants of health and equity, and comparative studies between Canada and Japan. She is an avid qualitative researcher, who uses a range of qualitative methodologies in her community and public health research. 